\title{
Childhood encephalitis in Canada in 2015
}

\author{
Ari Bitnun MD MSc FRCPC ${ }^{1}$, Susan E Richardson MD FRCPC ${ }^{2}$
}

$\mathrm{T}$ here are few conditions more devastating than severe encephalitis, in which a previously healthy child progresses, within days, from a nonspecific and apparently benign febrile illness to coma, seizure and irreversible brain injury. The current article focuses on key aspects of the etiology and management of acute and subacute childhood encephalitis beyond the neonatal period in the Canadian context. Several recent publications provide comprehensive reviews on the diagnostic approach to suspected encephalitis in both children and adults $(1,2)$.

Strictly speaking, a diagnosis of encephalitis requires proof of brain inflammation. However, in practice, the diagnosis is usually a clinical one, based on the presence of symptoms and signs including fever, headache, seizure or altered consciousness, and indirect evidence of brain inflammation such as cerebrospinal fluid (CSF) pleocytosis, elevated CSF protein level or suggestive neuroimaging abnormalities. Reduced consciousness - the hallmark of encephalopathy - is present in most cases of encephalitis, but can also be observed with other infections, infectious disorders including metabolic, immunological, toxic and drug-related conditions. A case definition for encephalitis has been proposed both as an aid to diagnosis and to enable future research studies to be more comparable with one another (Table 1) (1).

The incidence of encephalitis in developed countries ranges from 0.7 to 13.8 per 100,000 population (3). In a United Kingdom study, incidence rates varied from 1.5 per 100,000 overall to 2.8 per 100,000 for children and 8.7 per 100,000 for infants (4). The incidence of encephalitis due to specific pathogens is dynamic, influenced by a variety of factors including vaccination rates for diseases such as measles, mumps and varicella; geographical spread of vector-borne pathogens due to climate change or inadvertent air/ship transport, as occurred with the introduction of West Nile virus into North America; and the emergence of previously unknown zoonotic pathogens (eg, Nipah virus).

Pathogenesis varies according to etiology. Classic viral encephalitis due to herpes simplex virus (HSV), enteroviruses and arboviruses is necrosis of neurons or other cells. Measles, mumps and Mycoplasma pneumoniae can cause both acute encephalitis due to direct invasion of the CNS and postinfectious immune-mediated encephalitis. Influenza and other respiratory virus-associated encephalitides may involve excessive production of proinflammatory cytokines, mitochondrial dysregulation or endothelial dysfunction (3). Acute disseminated encephalomyelitis (ADEM) is likely a consequence of autoimmunity, although the precise mechanisms are not fully understood. Development of antibodies directed against the $N$-methyl-D-aspartate receptor (NMDAR) is responsible for anti-NMDAR encephalitis. Post-HSV encephalitis 'neurological relapse' (typically characterized reaction (PCR) testing is negative, has been attributed to the production of anti-NMDAR antibodies or, less frequently, anti-dopamine-2 receptor antibodies $(5,6)$. such as bacterial meningitis, sepsis or malaria, and with numerous noncaused by direct infection of the central nervous system (CNS) and by choreoathetoid movements), in which HSV CSF polymerase chain

A confirmed or probable etiology can be identified in 30\% to $60 \%$ of acute childhood encephalitis cases. The most common infectious causes in otherwise healthy Canadian children are HSV, varicella zoster virus (VZV), Epstein Barr virus (EBV), M pneumoniae and influenza, adenovirus and other respiratory viruses (Table 2). Arboviruses endemic to North America and entero-/parechoviruses are important considerations during the summer and fall months $(7-10)$, whereas influenza and other respiratory viruses are more typically observed during the winter months. M pneumoniae encephalitis can be observed year-round, with increased incidence coinciding with epidemic respiratory disease every three to seven years (11). Less commonly encountered pathogens include measles, mumps, rabies, Bartonella henselae, Baylisascaris procyonis and travel-related arboviruses, Rickettsia and free-living amoebae. ADEM and anti-NMDAR encephalitis are the predominant noninfectious causes of encephalitis in children, together accounting for approximately $15 \%$ to $25 \%$ of all encephalitis cases, respectively $(3,12)$. A review of cases involving patients $<30$ years of age referred to the California Encephalitis Project suggested that the frequency of anti-NMDAR encephalitis was higher than any single viral etiology (12). The main causes of subacute encephalitis in children are shown in Table 3.

In the immunocompromised host, herpes-group viruses (including HSV, VZV, EBV, cytomegalovirus and human herpes virus-6 [HHV-6]), enteroviruses and polyoma JC virus (progressive multifocal

\section{TABLE 1}

Diagnostic criteria for encephalitis and encephalopathy of presumed infectious or autoimmune etiology*

\begin{tabular}{l} 
Major criterion (required) \\
\hline Altered mental status, defined as decreased or altered level of \\
consciousness, lethargy, or personality change lasting $\geq 24 \mathrm{~h}$ with no \\
alternative cause identified \\
Minor criteria (two for possible encephalitis, $\geq 3$ for probable or \\
confirmed encephalitis) ${ }^{\dagger}$ \\
\hline Documented fever $\geq 38.0^{\circ} \mathrm{C}\left(100.4^{\circ} \mathrm{F}\right)$ within $72 \mathrm{~h}$ before or after \\
presentation \\
Generalized or partial seizures not attributable to a pre-existing seizure \\
disorder \\
New onset of focal neurological findings \\
Cerebrospinal fluid pleocytosis (leukocyte count $\left.\geq 5 \times 10^{6} / \mathrm{L}\right)$ \\
Abnormality of brain parenchyma on neuroimaging suggestive of encephalitis \\
that is either new from previous studies or appears to be acute in onset \\
Abnormality on electroencephalography that is consistent with encephalitis \\
and not attributable to another cause \\
${ }^{*}$ Adapted from reference $1 ;{ }^{+}$Confirmed encephalitis requires: pathological \\
confirmation of brain inflammation consistent with encephalitis; pathological, \\
microbiological or serological evidence of acute infection with a microorgan- \\
ism that is strongly associated with encephalitis from an appropriate clinical \\
specimen; or laboratory evidence of an autoimmune condition that is strongly \\
associated with encephalitis
\end{tabular}

${ }^{1}$ Division of Infectious Diseases, Hospital for Sick Children; Department of Paediatrics, University of Toronto; ${ }^{2}$ Division of Microbiology,

Department of Paediatric Laboratory Medicine, Hospital for Sick Children, University of Toronto, Toronto, Ontario

Correspondence: Dr Ari Bitnun, Division of Infectious Diseases, Hospital for Sick Children, 555 University Avenue, Toronto, Ontario

M5G 1X8. Telephone 416-813-7654 ext 206268, fax 416-813-8404, e-mail ari.bitnun@sickkids.ca

This open-access article is distributed under the terms of the Creative Commons Attribution Non-Commercial License (CC BY-NC) (http:/ 
TABLE 2

Selected clinical, microbiological and treatment aspects of infectious causes of childhood encephalitis acquired in Canada Cause Comments

HSV $(5,6,22) \quad$ PCR of CSF can be negative during the first $72 \mathrm{~h}$ of illness; repeat lumbar puncture if clinical picture is consistent with HSV encephalitis. Treatment: intravenous acyclovir 30-60 mg/kg/day for children three months to 12 years of age and $30 \mathrm{mg} / \mathrm{kg} /$ day for children $\geq 12$ years of age in three divided doses for three weeks*. Testing for anti-NMDAR antibodies in CSF and serum is warranted for new-onset postencephalitis neurological symptoms. Corticosteroids may be of benefit for post-HSV encephalitis symptomatic relapse if CSF tests negative for HSV by PCR and there are no new necrotic lesions on MRI

EBV (24) Serology is the mainstay of diagnosis (monospot; IgM and IgG VCA; IgG EA, VCA and EBNA). Detection of EBV by PCR in CSF may represent true disease or virus DNA within passenger lymphocytes. Treatment: intravenous ganciclovir $10 \mathrm{mg} / \mathrm{kg} /$ day in two divided doses for 2-3 weeks should be considered for severe cases; complete resolution without treatment is common

VZV (25) Concurrent or recent chickenpox in majority ${ }^{\dagger}$. CSF PCR is negative in $75 \%$ of children. Treatment: intravenous acyclovir - for children $\geq 2$ years of age, $80 \mathrm{mg} / \mathrm{kg}$ per day in four divided doses (max $3200 \mathrm{mg} / \mathrm{day}$ ) if $\leq 40 \mathrm{~kg}, 3200 \mathrm{mg}$ in four divided doses if $>40 \mathrm{~kg}$ for $1-3$ weeks ${ }^{\ddagger}$

HHV-6 Restricted to immunocompromised subjects. Detection of HHV-6 in CSF by PCR may represent true infection or latent virus within lymphocytes or DNA integration related to vertical germline transmission. Treatment: intravenous ganciclovir $10 \mathrm{mg} / \mathrm{kg} / \mathrm{day}$ in two divided doses for 2-6 weeks should be considered (foscarnet is an alternative agent if ganciclovir is contraindicated).

HHV-7 (26) Rare; mainly teenagers and young adults. Majority of positive CSF PCR test results associated with latent infection (eg, likely false positive with respect to encephalitis causation); microbiological diagnosis requires confirmation of seroconversion (not available commercially). No data regarding treatment are available

Entero/ Parechovirus disease generally restricted to those $<3$ months of age. Most children with parechovirus encephalitis do not demonstrate parechovi- pleocytosis. CSF PCR for enteroviruses relatively insensitive; testing of respiratory samples and stool recommended. Treatment: IVIG may

ruses be considered for severe cases, but evidence is inconclusive; pleconaril has activity against some serotypes of enterovirus but is currently not available

West Nile Serology is the mainstay of diagnosis (CSF and serum); may be negative early in course or positive from remote infection. CSF and blood PCR virus (7) have poor sensitivity after neurological symptom onset

Other Powassan, Eastern equine, Western equine, St Louis and California serogroup (Snowshoe hare; Jamestown Canyon; La Crosse) encephalitis

arboviruses viruses§. Serological diagnosis (requires acute and convalescent serum); consider in summer and fall

$(8,10,18,27)$

Rabies (28) Diagnostic tests include serology on serum and CSF, RT-PCR or virus isolation from saliva, detection of rabies antigen in cutaneous nerves (nape of neck skin biopsy), or brain biopsy. Treatment: Full recovery has been observed with pharmacologically induced coma with ketamine and midazolam plus antiviral therapy (amantadine or ribavirin)

Influenza A Abrupt onset before or concurrent with respiratory symptom onset in some cases. Acute necrotizing encephalopathy is a severe form of disease and $\mathrm{B}^{\pi} \quad$ including bilateral symmetric necrosis of the thalami, putamina and cerebral and cerebellar white matter on MRI. PCR on CSF is almost uniformly negative. Treatment: oseltamivir according to weight for 5-10 days.

Measles Occurs in children who are incompletely immunized. Cough, coryza, conjunctivitis, erythematous maculopapular rash, Koplik spots. Serology and direct detection by PCR in CSF, nasopharyngeal and urine samples

Mumps Occurs in children who are incompletely immunized. Parotitis, testicular pain. Serology and direct detection by PCR in CSF, saliva

Mycoplasma Absence of a respiratory prodrome does not preclude as a cause. Both direct and immune-mediated pathogenesis hypothesized. PCR of CSF

pneumoniae and respiratory samples plus serology in peripheral blood recommended for diagnosis; due to poor specificity and predictive value, serology

$(11,23) \quad$ should not be relied upon in isolation for diagnosis. Treatment: A 10-14 day course of antimycoplasmal antibiotic therapy may be considered; role of corticosteroids uncertain

Bartonella Consider in those with exposure to cats. Serology is the mainstay of microbiological diagnosis. PCR available, but utility in diagnosis of

henselae encephalopathy/encephalitis unknown. Treatment: doxycycline or cotrimoxazole plus rifampin for 4-6 weeks may be considered

Baylisascaris Consider in toddlers or cognitively impaired children with exposure to soil potentially contaminated with raccoon feces. Peripheral blood and

procyonis CSF eosinophilia. Serology is the mainstay of microbiological diagnosis. Treatment: albendazole for 4 weeks plus corticosteroids with taper (19) may be of benefit

${ }^{*}$ The 2012 Red Book recommends a dose of $30-45 \mathrm{mg} / \mathrm{kg} /$ day in three divided dose for children three months to 12 years of age. However, some experts prefer to use the upper limit of the approved dose range (60 mg/kg/day in three divided doses) for children <12 years of age; close monitoring of renal function is required; IIn adults, herpes zoster-associated encephalitis predominates (mainly in immunocompromised hosts); $¥$ Some experts prefer to use $1500 \mathrm{mg} / \mathrm{m}^{2} / \mathrm{day}$ in three divided doses, the dose usually used to treat varicella in immunocompromised hosts; duration of therapy has not been well established, and close monitoring of renal function is required; §Eastern equine and Powassan encephalitis viruses are a consideration primarily in the eastern provinces; Western equine encephalitis predominantly in the western and prairie provinces and into Ontario; St Louis and the California serogroup viruses (Snowshoe hare and Jamestown Canyon) encephalitis viruses are more ubiquitous; " OOther respiratory viruses, including adenovirus, parainfluenza viruses and respiratory syncytial virus, are occasionally associated with encephalitis or infection-associated encephalopathy. CSF Cerebrospinal fluid; EA Early antigen; EBNA Epstein Barr nuclear antigen; EBV Epstein Barr virus; HHV-6 Human herpes virus-6; HHV-7 Human herpes virus-7; HSV Herpes simplex virus; Ig Immunoglobulin; IVIG Intravenous immunoglobulin; MRI Magnetic resonance imaging; NMDAR N-methyl-D-aspartate receptor; PCR Polymerase chain reaction; RT-PCR Reverse transcriptase PCR; VCA Viral capsid antigen; VZV Varicella zoster virus

leukoencephalopathy) are important considerations. Of note, the absence of rash does not preclude VZV as a cause of encephalitis in severely immunocompromised individuals; elevated liver enzyme levels can serve as a clinical indicator in this circumstance. Measles inclusion body encephalitis is typically observed within one year of measles virus infection or measles vaccination in children with primary or secondary immune deficiency $(13,14)$. Encephalitis due to West Nile virus and rabies has been observed in adults following organ transplantation from an infected donor $(15,16)$.
Travel-related viral encephalitides, not endemic to Canada, should be considered if symptom onset began within three to four weeks of leaving the region (1-3,17). Japanese encephalitis virus, endemic to Japan, Korea, Taiwan, China, Southeast Asia, India, Nepal and northern Australia, is a predominant travel-related pathogen (18). Rural travel during the summer months to central or northern Europe or Russia, including Siberia, should lead to consideration of tick-borne encephalitis virus. Nipah virus infection is acquired following close contact with swine, bats or bat roosting sites, or infected 
humans in south Asia. Recent travel to Australia or New Guinea suggests the possibility of encephalitis due to Murray Valley virus or Hendra virus, the latter being associated with contact with horses. Rift Valley fever virus can be acquired from mosquito bites, or direct or indirect contact with animals or animal products (including carcasses) in sub-Saharan Africa or the Arabian Peninsula. Dengue and Chikungunya viruses are rare causes of encephalitis that can be acquired in many tropical and subtropical regions, including the Caribbean. Other considerations include herpes B virus in cases with a history of bite or scratch by a macaque monkey (old world), Toscana virus transmitted by sandflies in Mediterranean countries, Tahyna virus in Russia and other parts of Europe, and Venezuelan equine encephalitis virus endemic to central and South America.

The microbiological investigation of the previously well child with acute encephalitis need not be exhaustive and should be tailored to the history and findings on physical examination (1-3). PCR testing of CSF for HSV, EBV, entero-/parechoviruses and M pneumoniae and of respiratory samples for $M$ pneumoniae and entero-/parechoviruses is recommended for all cases. Stool should be tested for enteroviruses and adenovirus. Serology on peripheral blood for acute EBV and $\mathrm{M}$ pneumoniae infection should also be performed, and an acute serum sample stored for subsequent testing for less commonly encountered pathogens (1). Serological testing of serum and CSF for West Nile virus and other endemic arboviruses should be performed when disease onset is during the summer and fall months. In the presence of respiratory symptoms, respiratory samples should be tested for influenza A and $\mathrm{B}$, adenoviruses, parainfluenza viruses, respiratory syncytial virus and rhinoviruses. A vesicular rash should prompt testing of lesion samples for HSV, VZV and selectively for enteroviruses by PCR (or culture). Serology and PCR testing of CSF as well as respiratory or salivary samples for measles and mumps is warranted in children with suggestive clinical findings. Baylisascaris procyonis serology is appropriate for toddlers or autistic/developmentally delayed children with peripheral or CSF eosinophilia, particularly if there is a history of pica or playing in soil frequented by raccoons (19). In case of travel, a detailed history that includes precise travel dates, specific regions visited (rural versus urban), any documented exposures to arbovirus vectors, animals (including bites or scratches), or swimming in lakes and brackish water should direct testing for travel-related infections (1-3).

Treatment of acute childhood encephalitis begins with meticulous supportive care that includes management of fluid and electrolytes, respiratory status, seizures and increased intracranial pressure. Intravenous acyclovir should be given to all children pending microbiological test results (Table 2). A full three-week course of therapy should be administered if HSV disease is confirmed or if the clinical picture is most compatible with HSV encephalitis regardless of PCR results, particularly if the lumbar puncture was performed within $72 \mathrm{~h}$ of symptom onset. Treatment directed at other pathogens should be considered, although efficacy is less well established (Table 2). Firstline therapy for ADEM and anti-NMDAR encephalitis consists of high-dose corticosteroids; other treatment modalities include intravenous immunoglobulin, plasma exchange and, for refractory cases of anti-NMDAR encephalitis, rituximab (20). Excision of ovarian teratoma or other tumours associated with anti-NMDAR encephalitis speeds up clinical response and reduces relapses (21).

The risk for death and permanent neurological sequelae including cognitive impairment, psychiatric or behavioural disorders, epilepsy, motor dysfunction, cranial nerve deficits or movement disorders vary according to etiology. Rabies encephalitis, subacute sclerosing panencephalitis, measles inclusion-body encephalitis, rubella panencephalitis and non-HIV-associated progressive multifocal leukoencephalopathy are almost uniformly fatal. Although mortality is now uncommon, neurological sequelae occur in 50\% to $60 \%$ or more of children with HSV encephalitis despite acyclovir treatment (22). The outcome of M pneumoniae-associated encephalitis is similarly poor, with $50 \%$ to $60 \%$ of children experiencing sequelae (23). Death or neurological sequelae following arboviral encephalitis
TABLE 3

Selected causes, clinical features and diagnostic tests for subacute childhood encephalitis*

\begin{tabular}{ll}
\hline Condition & Selected clinical features and diagnostic methods \\
\hline Anti-NMDAR & Female preponderance (70\%) \\
encephalitis ${ }^{\dagger}$ & Psychiatric or behavioural symptoms, seizures, \\
& movement disorder, catatonia, hallucinations \\
& Anti-NMDAR antibodies present in CSF and \\
& selectively in serum \\
& Teratoma, other tumours should be sought, but are \\
& uncommon in children <12 years of age (regardless \\
& of sex) and in boys of any age \\
\hline Subacute sclerosing & Onset typically between 5-15 years of age \\
panencephalitis & Cognitive decline, personality change, strange \\
& behaviour, myoclonic jerks, seizures, dementia \\
& Electroencephalography showing periodic complexes \\
& Elevated CSF, serum anti-measles titers (CSF/serum \\
titre ratio typically <200)
\end{tabular}

${ }^{*}$ Other infections that can rarely present with a subacute/chronic encephalitic picture in childhood include HIV, Mycobacterium tuberculosis, congenital syphilis and variant Creutzfeldt-Jakob disease; 'Encephalitis due to other autoantibodies to neuronal surface $(\gamma$-aminobutyric acid-A receptor, $\gamma$-aminobutyric acid- $B$ receptor, $\alpha$-amino-3-hydroxy-5-methyl-4isoxazoleproprionic acid receptor, leucine-rich glioma inactivated protein 1 , contactin-associated protein-like 2, dipeptidyl-peptidase-like protein-6) and intracellular (Hu, collapsin response mediator proteins, amphiphysin, Ri, Ma2, GAD65) antigens are rare in children. CSF Cerebrospinal fluid; Ig Immunoglobulin; NMDAR N-methyl-D-aspartate receptor; PCR Polymerase chain reaction; PML Progressive multifocal leukoencephalopathy

varies from $50 \%$ to $70 \%$ for Eastern equine and Powassan encephalitis to $10 \%$ to $30 \%$ for Japanese, St Louis, Western equine and La Crosse encephalitis $(8-10,18)$. Most children with ADEM respond to immune-modulation, but approximately $20 \%$ experience relapses, some of whom are eventually diagnosed with multiple sclerosis. With appropriate treatment, $85 \%$ of children with anti-NMDAR encephalitis demonstrate either complete recovery $(60 \%)$ or minimal residual deficits (25\%) (6).

Significant challenges remain in the diagnosis and management of childhood encephalitis. Standardizing diagnostic algorithms and enhancing the microbiological investigative capability of laboratories around the country would be an important first step in enhancing diagnostic yield. Future research needs include discovery of new infectious and noninfectious causes, improving our understanding of pathogenesis and determining optimal etiology-specific therapeutic regimens. 


\section{REFERENCES}

1. Venkatesan A, Tunkel AR, Bloch KC, et al. Case definitions, diagnostic algorithms, and priorities in encephalitis: Consensus statement of the International Encephalitis Consortium. Clin Infect Dis 2013;57:1114-28.

2. Tunkel AR, Glaser CA, Bloch KC, et al. The management of encephalitis: Clinical practice guidelines by the Infectious Diseases Society of America. Clin Infect Dis 2008;47:303-27.

3. Glaser CA, Venkatesan A. Encephalitis. In: Scheld WM, Whitley RJ, Marra CM, eds. Infections of the Central Nervous System. Philadelphia: Wolters Kluwer, 2014:84-111.

4. Davison KL, Crowcroft NS, Ramsay ME, Brown DW, Andrews NJ. Viral encephalitis in England, 1989-1998: What did we miss? Emerg Infect Dis 2003;9:234-40.

5. Pruss H, Finke C, Holtje M, et al. N-methyl-D-aspartate receptor antibodies in herpes simplex encephalitis. Ann Neurol 2012;72:902-11.

6. Titulaer MJ, Leypoldt F, Dalmau J. Antibodies to N-methyl-D-aspartate and other synaptic receptors in choreoathetosis and relapsing symptoms post-herpes virus encephalitis. Mov Disord 2014;29:3-6.

7. Oyer RJ, David Beckham J, Tyler KL. West Nile and St. Louis encephalitis viruses. Handb Clin Neurol 2014;123:433-47.

8. Gholam BI, Puksa S, Provias JP. Powassan encephalitis: A case report with neuropathology and literature review. CMAJ 1999;161:1419-22.

9. Greenlee JE. The equine encephalitides. Handb Clin Neurol 2014;123:417-32.

10. Rust RS, Thompson WH, Matthews CG, Beaty BJ, Chun RW. La Crosse and other forms of California encephalitis. J Child Neurol 1999;14:1-14.

11. Bitnun A, Richardson SE. Mycoplasma pneumoniae: Innocent bystander or a true cause of central nervous system disease? Curr Infect Dis Rep 2010;12:282-90.

12. Gable MS, Sheriff H, Dalmau J, Tilley DH, Glaser CA. The frequency of autoimmune $\mathrm{N}$-methyl-D-aspartate receptor encephalitis surpasses that of individual viral etiologies in young individuals enrolled in the California Encephalitis Project. Clin Infect Dis 2012;54:899-904.

13. Freeman AF, Jacobsohn DA, Shulman ST, et al. A new complication of stem cell transplantation: Measles inclusion body encephalitis. Pediatrics 2004;114:e657-660.

14. Bitnun A, Shannon P, Durward A, et al. Measles inclusion-body encephalitis caused by the vaccine strain of measles virus. Clin Infect Dis 1999;29:855-61.
15. Iwamoto M, Jernigan DB, Guasch A, et al. Transmission of West Nile virus from an organ donor to four transplant recipients. N Engl J Med 2003;348:2196-203.

16. Srinivasan A, Burton EC, Kuehnert MJ, et al. Transmission of rabies virus from an organ donor to four transplant recipients. N Engl J Med 2005;352:1103-11.

17. Solomon T, Patabendige A, Whitley RJ. Arthropod-borne viral encephalitis. In: Scheld WM, Whitley RJ, Marra CM, eds. Infections of the central nervous system. Philadelphia: Wolters Kluwer, 2014:210-38.

18. Griffiths MJ, Turtle L, Solomon T. Japanese encephalitis virus infection. Handb Clin Neurol 2014;123:561-76.

19. Hajek J, Yau Y, Kertes P, et al. A child with raccoon roundworm meningoencephalitis: A pathogen emerging in your own backyard? Can J Infect Dis Med Microbiol 2009;20:e177-80.

20. Armangue T, Titulaer MJ, Malaga I, et al. Pediatric anti-N-methylD-aspartate receptor encephalitis-clinical analysis and novel findings in a series of 20 patients. J Pediatr 2013;162:850-6, e852.

21. Titulaer MJ, McCracken L, Gabilondo I, et al. Treatment and prognostic factors for long-term outcome in patients with anti-NMDA receptor encephalitis: An observational cohort study. Lancet Neurol 2013;12:157-65.

22. Whitley RJ, Kimberlin DW. Herpes simplex encephalitis: Children and adolescents. Sem Pediatr Infect Dis 2005;16:17-23.

23. Bitnun A, Ford-Jones EL, Petric M, et al. Acute childhood encephalitis and Mycoplasma pneumoniae. Clin Infect Dis 2001;32:1674-84.

24. Doja A, Bitnun A, Jones EL, et al. Pediatric Epstein-Barr virus-associated encephalitis: 10-year review. J Child Neurol 2006;21:385-91.

25. Science M, MacGregor D, Richardson SE, Mahant S, Tran D, Bitnun A. Central nervous system complications of varicella-zoster virus. J Pediatr 2014;165:779-85.

26. Schwartz KL, Richardson SE, Ward KN, et al. Delayed primary HHV-7 infection and neurologic disease. Pediatrics 2014;133:e1541-7.

27. Silverman MA, Misasi J, Smole S, et al. Eastern equine encephalitis in children, Massachusetts and New Hampshire, USA, 1970-2010. Emerg Infect Dis 2013;19:194-201.

28. Recovery of a patient from clinical rabies - California, 2011. MMWR Morb Mortal Wkly Rep 2012;61:61-5. 


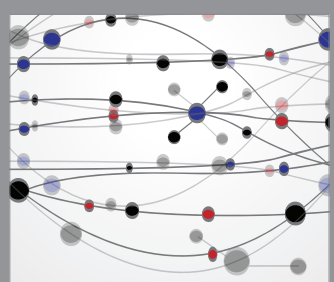

The Scientific World Journal
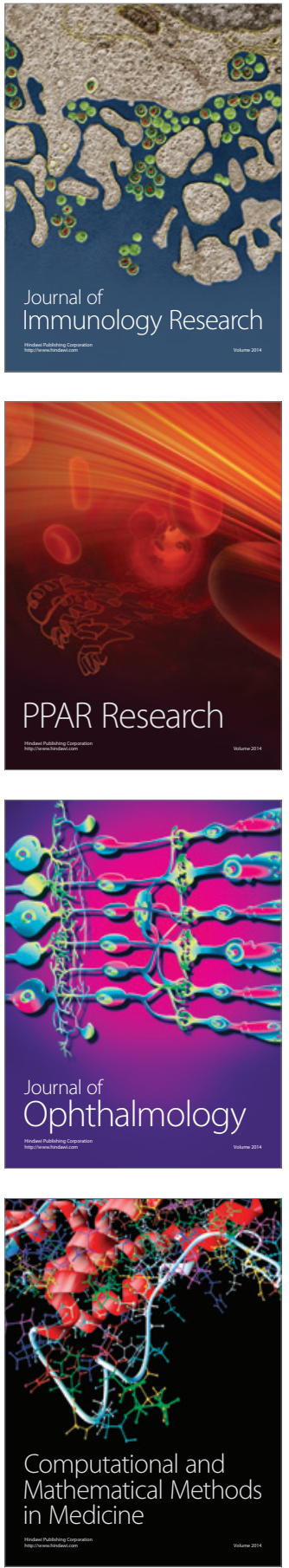

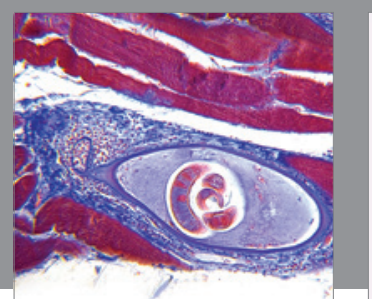

Gastroenterology Research and Practice

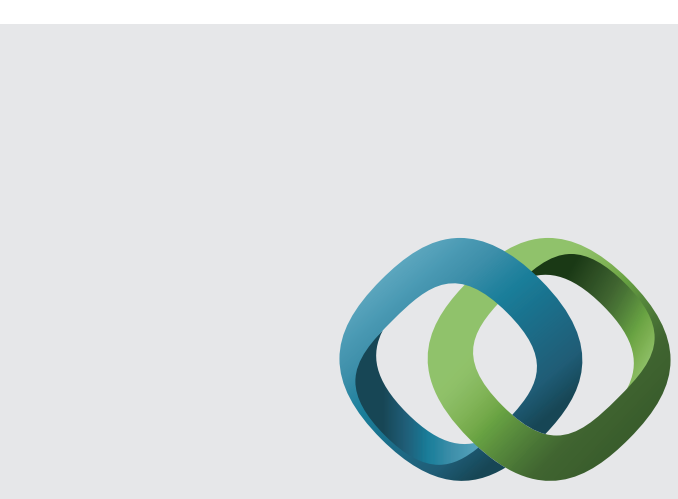

\section{Hindawi}

Submit your manuscripts at

http://www.hindawi.com
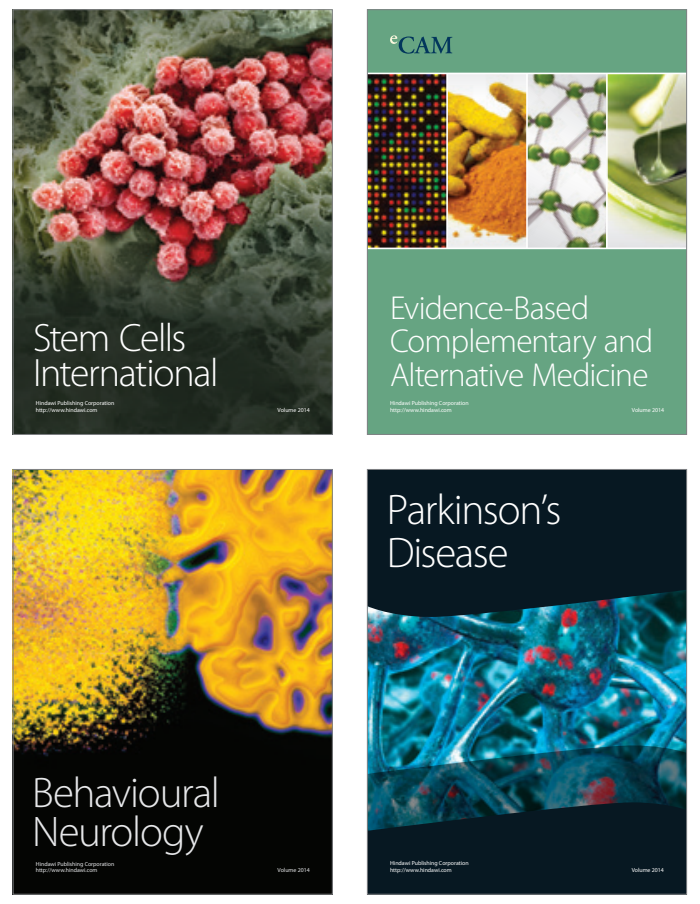
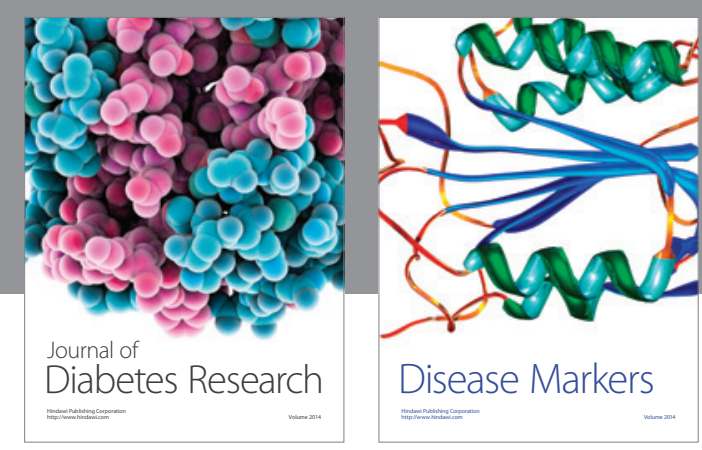

Disease Markers
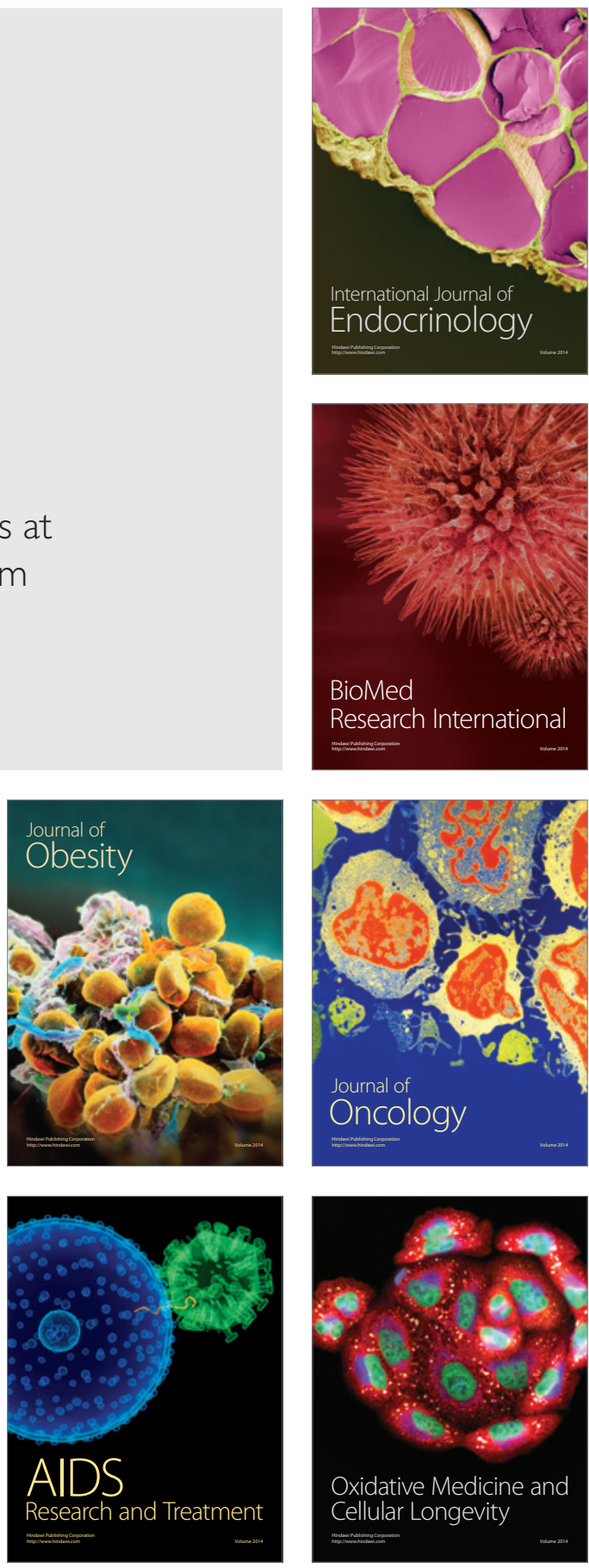